\title{
The Angiographic Anatomy of the Sphenoidal Segment of the Middle Cerebral Artery and Its Relevance in Mechanical Thrombectomy
}

\author{
Rakesh Khatri Mohtashim Arbaab Qureshi Mohammad Rauf A. Chaudhry \\ Alberto Maud Anantha Ramana Vellipuram Salvador Cruz-Flores \\ Gustavo Jose Rodriguez
}

Department of Neurology, Texas Tech University of Health Sciences Center, El Paso, TX, USA

\section{Keywords}

Middle cerebral artery · Sphenoidal segment · Main trunk $\cdot$ M1 segment $\cdot$ Middle cerebral artery classification

\begin{abstract}
Objective: The middle cerebral artery (MCA) is the most commonly treated artery in mechanical thrombectomy stroke trials; however, there is no pragmatic agreement about the segmental anatomy and nomenclature utilized. It results in significant clinical-radiological dissociation and introduces bias in research trials. The purpose of the study is to review and compare angiographic anatomy with microsurgical anatomy literature of the MCA with emphasis on the discrepancy. Methodology: Consecutive cerebral angiograms between January 2011 and March 2014 were retrospectively reviewed by endovascular surgical neuroradiologists. Information about the anatomy of the sphenoidal segment of the MCA classified as classic and non-classic pattern, the lenticulostriate artery takeoff pattern, and the course angulation of the sphenoidal segment were studied. Results: A total of 500 patients, 886 cerebral angiograms, were reviewed. We found the classic pattern of the main trunk MCA bifurcation and a straight angulation course in less than half of the cases. The lenticulostriate arteries arose not
\end{abstract}

Portions of the work have been presented in poster form at the Society of Vascular and Interventional Neurology (SVIN) 9th Annual Meeting, New York Marriot Brooklyn Bridge in Brooklyn, NY, November 17, 2016; at the International Stroke Conference, 2017; George R. Brown Convention Center, Houston, TX, February 23rd, 2017; and at the American Academy of Neurology 69th Annual Meeting, Boston Convention and Exhibition Center, Boston, MA, April 27, 2017.

Portions of the work have been presented in oral form at the 26th European Stroke Conference, Berlin, Germany, on May 25, 2017. 
Khatri et al.: The Angiographic Anatomy of the Sphenoidal Segment of the Middle

only from the main trunk but also from its divisions in more than half of the cases. Conclusion: It is important to corroborate our findings and to develop a pragmatic classification to accurately assess MCA occlusions from the radiological and clinical perspective.

(c) 2019 S. Karger AG, Basel

\section{Introduction}

The middle cerebral artery (MCA) is the most commonly treated cerebral artery using mechanical thrombectomy [1]. Indeed, robust data on recanalization rates using stent retrievers was obtained from well-designed trials focused on the MCA recanalization. Despite the fact that the MCA has been the subject of comprehensive research, there is no consensus about the anatomy and nomenclature utilized to describe the site of occlusion within the MCA [2-4].

In 1938, Fischer [2] originally named the sphenoidal segment as the M1 segment. The M1 segment, horizontal in its course, could or could not include the main bifurcation of the MCA; in such case, a pre-bifurcation and post-bifurcation M1 segment would be present. At the genu, and coinciding with a change in plane, the insular segment initiates its vertical course and classically described as genu includes the origin of the main MCA divisions. More recently, and with the advent of acute endovascular treatment for ischemic stroke, in most instances it has arbitrarily been assigned as follows: the main MCA trunk as the M1 segment and the main MCA divisions as the M2 segments [5]. It is widely presumed about the MCA anatomy that the horizontal segment is straight, its major MCA bifurcation occurs at the genu, and bifurcation also typically occurs distal to the lenticulostriate arteries (LSAs) takeoff [3]. However large anatomical studies addressing this issue are lacking and most of them are based on small cadaveric series.

Our purpose is to evaluate, based on angiography, the frequency of the anatomical variations of the sphenoidal segment according to the site of the main MCA bifurcation, the origin of the LSAs, and the sphenoidal segment course pattern.

\section{Methods}

Consecutive patients undergoing cerebral angiography for different reasons between January 2011 and March 2014 were selected for the study. We included patients undergoing cerebral angiography without any known mass effect on brain imaging (head computed tomography scan and/or brain magnetic resonance imaging) or other notable intracranial pathology such as intracranial aneurysms, dissections, stenosis, vasculitis, arteriovenous malformations, or any lesion that could distort the normal architecture and integrity of the vessels for the purpose of precise visualization of the MCA vascular anatomy.

Angiographic examinations were performed using a commercially available biplanar angiographic unit (Integris Allura; Philips Medical Systems, Best, the Netherlands). Standard anteroposterior (AP) and lateral cerebral angiograms were selected from the integration of Picture Archiving and Communication Systems (PACS) program by one of the authors (M.A.Q) and were verified by three experienced endovascular surgical neuroradiologists (G.J.R., A.M., R.K.) and classified using previously described landmarks as follows.

\section{Angiographic Sylvian Point}

The point of bifurcation of the sphenoidal segment was noted by drawing a perpendicular line from the angiographic Sylvian point (ASP). The ASP is defined as the point where the last main branch, which is usually the angular branch of the MCA, leaves the posterior end of the insula, turning inferolaterally to reach the surface of the brain. This point approximates the apex of the insula and represents the posterior limit of the Sylvian fissure. The ASP normally lies 30 to $43 \mathrm{~mm}$ from the inner table of the skull on a routine AP view and is located at the halfway point on the clinoparietal line (points a, b) [6], as shown in Figure 1. 


\section{Interventional} Neurology

Fig. 1. a, b Angiographic Sylvian point. The ASP normally lies 30$43 \mathrm{~mm}$ from the inner table of the skull on a routine AP view and is located at the halfway point on the clinoparietal line (points a, b).

\begin{tabular}{l|l}
\hline Intervent Neurol 2019;8:231-241 \\
\hline DOI: 10.1159/000502545 & $\begin{array}{l}\text { @ 2019 S. Karger AG, Basel } \\
\text { www.karger.com/ine }\end{array}$ \\
\hline
\end{tabular}

Khatri et al.: The Angiographic Anatomy of the Sphenoidal Segment of the Middle Cerebral Artery and Its Relevance in Mechanical Thrombectomy

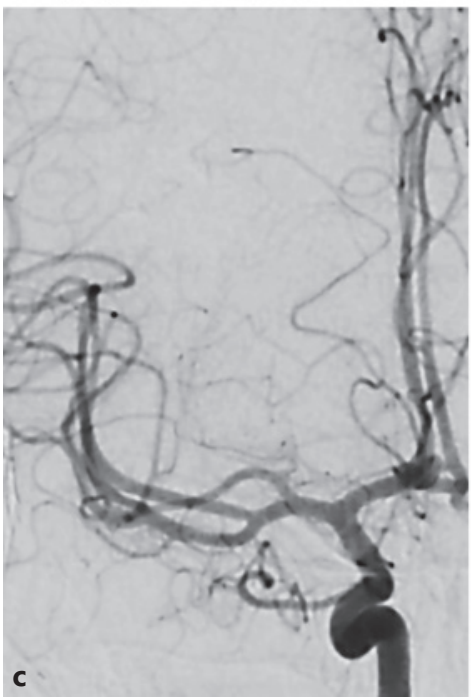

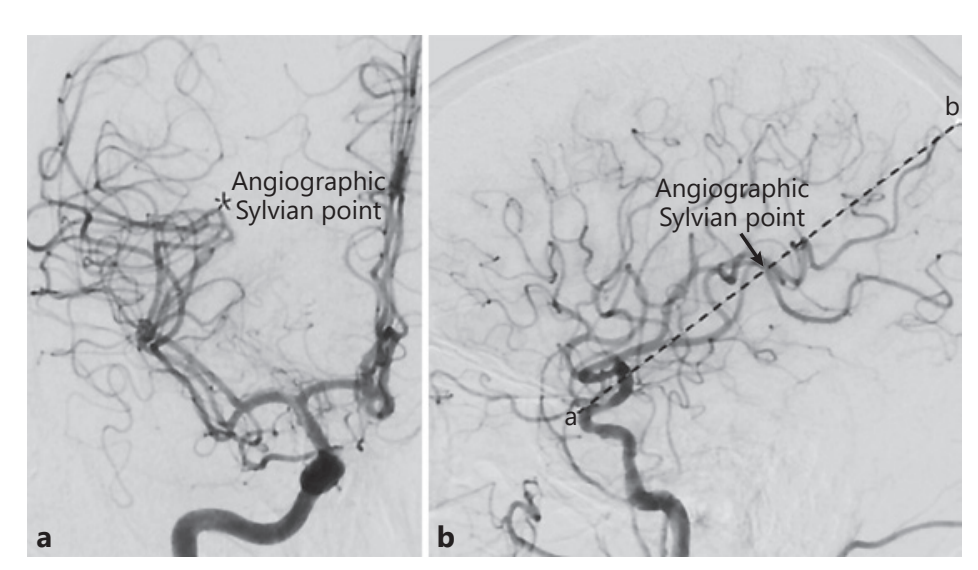
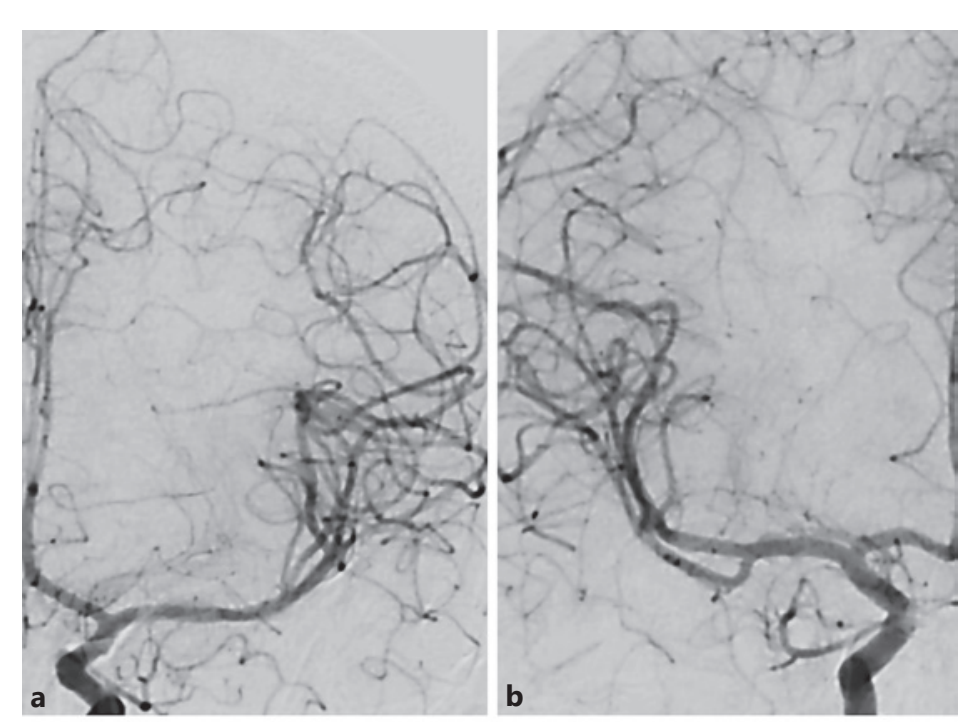

Fig. 2. a Classic bifurcation. b Non-classic bifurcation. c Early bifurcation.

\section{(}

\section{The Classic and Non-Classic MCA Bifurcation}

We classified the main MCA bifurcation as "classic" when the bifurcation occurred at the genu or junction between the horizontal and vertical segments (Fig. 2a), and as "non-classic" when the bifurcation occurred before the genu and therefore within the horizontal segment (Fig. 2b). "Early bifurcation" was defined as the bifurcation occurring within $10 \mathrm{~mm}$ from the origin of the sphenoidal segment or the terminal internal 
Interventional

Neurology
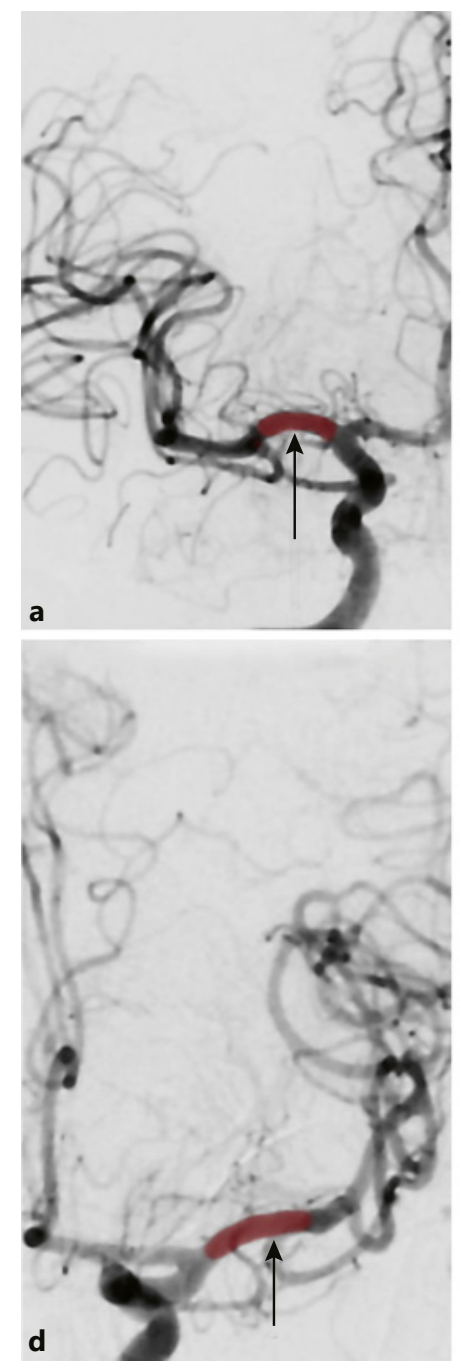

\begin{tabular}{l|l}
\hline Intervent Neurol 2019;8:231-241 \\
\hline DOI: 10.1159/000502545 & $\begin{array}{l}\text { ○ 2019 S. Karger AG, Basel } \\
\text { www.karger.com/ine }\end{array}$ \\
\hline
\end{tabular}

Khatri et al.: The Angiographic Anatomy of the Sphenoidal Segment of the Middle Cerebral Artery and Its Relevance in Mechanical Thrombectomy
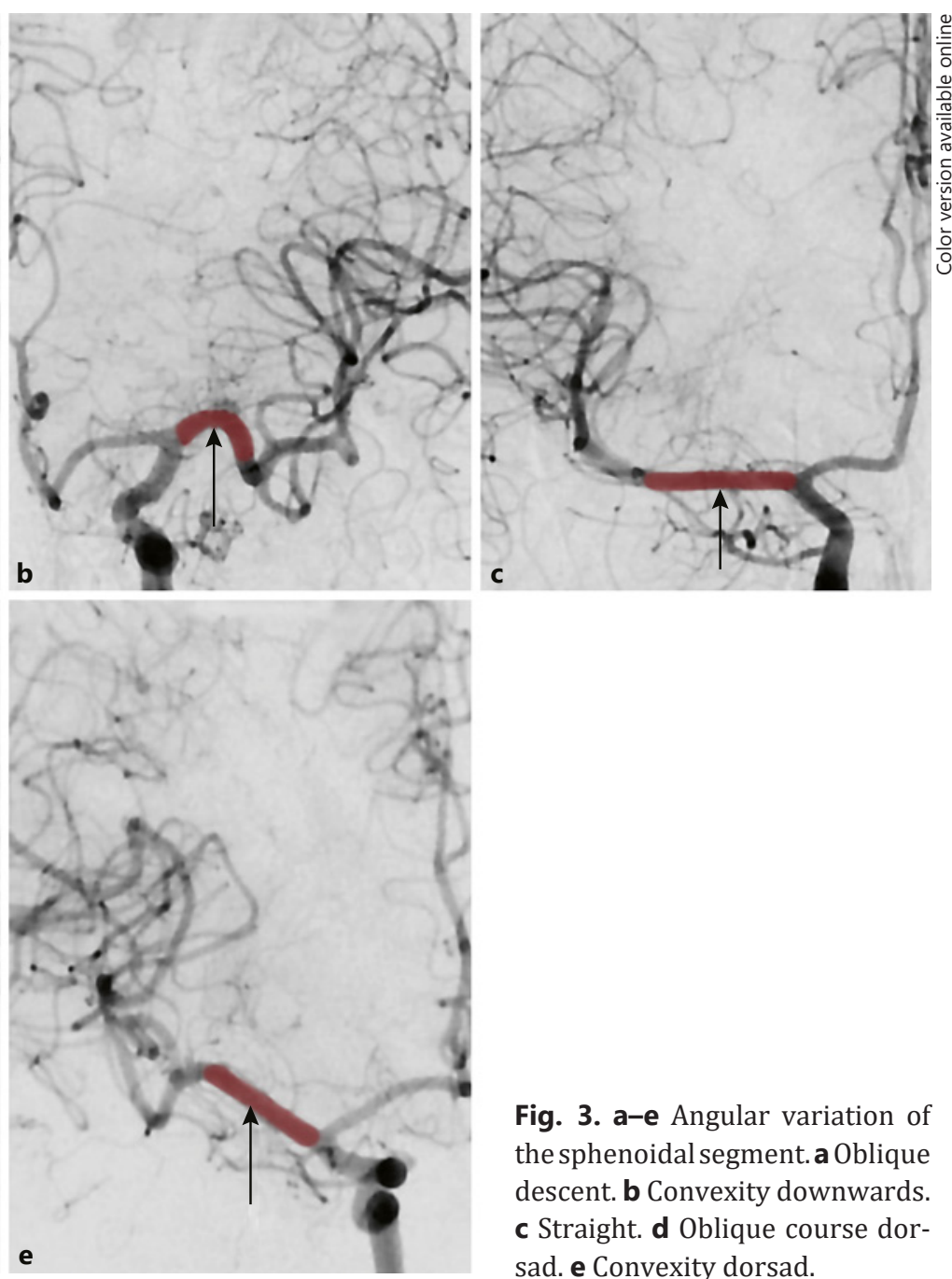

Fig. 3. a-e Angular variation of the sphenoidal segment. a Oblique descent. b Convexity downwards. c Straight. d Oblique course dorsad. e Convexity dorsad.

carotid artery (ICA) (Fig. 2c). The anterior temporal artery, regardless of its size, was not considered to determine the main MCA bifurcation pattern. The length of the main MCA trunk was measured, which is the distance from the origin of the MCA at the terminus ICA to the main MCA bifurcation.

\section{Sphenoidal Segment Course}

Angular variations of the sphenoidal segment were analyzed and classified into five groups as previously described [7]: (1) oblique descent; (2) convexity downwards; (3) straight; (4) oblique course dorsad; and (5) convexity dorsad (Fig. 3a-e). Furthermore, they were categorized according to the age groups.

\section{Lenticulostriate Arteries}

The takeoff of the LSAs was classified as pre- and/or post-bifurcation of the main MCA (main MCA trunk and/or MCA divisions, including the horizontal and/or vertical course of the divisions).

Furthermore, the anatomic similitude (mirroring) between the right and left MCA segments were studied in those patients with bilateral cerebral angiograms.

\section{Results}

A total of 500 patients were included for the study period that provided a total of 886 cerebral angiograms that were reviewed. Out of these, 386 patients had bilateral cerebral angiograms, and the remaining had unilateral cerebral angiograms, 55 on the left side and 59 
Table 1. MCA bifurcation patterns and sphenoidal segment trunk length (mm)

\begin{tabular}{|c|c|c|c|c|c|c|}
\hline & $\begin{array}{l}\text { Total } \\
(n=886 \\
\text { cerebral } \\
\text { angiograms) }\end{array}$ & $\begin{array}{l}\text { Right } \\
(n=445 \\
\text { cerebral } \\
\text { angiograms) }\end{array}$ & $\begin{array}{l}\text { Left } \\
(n=441 \\
\text { cerebral } \\
\text { angiograms) }\end{array}$ & $\begin{array}{l}\text { Length right } \\
\text { (mean } 13.4 \pm 4.8 \text { ) }\end{array}$ & $\begin{array}{l}\text { Length left } \\
\text { (mean } 13.6 \pm 5.0)\end{array}$ & $\begin{array}{l}\text { Length total } \\
\text { (mean } 13.5 \pm 4.9 \text { ) }\end{array}$ \\
\hline Classic & $423(47.7 \%)$ & $215(48.3 \%)$ & $208(47.2 \%)$ & $16.87( \pm 3.7)$ & $17.3( \pm 4.0)$ & $17.06( \pm 3.84)$ \\
\hline $\begin{array}{l}\text { Non-classic } \\
\text { Non-classic without }\end{array}$ & $463(52.2 \%)$ & $230(51.7 \%)$ & $233(52.8 \%)$ & $10.2( \pm 3.4)$ & $10.4( \pm 3.3)$ & $10.33( \pm 3.31)$ \\
\hline $\begin{array}{l}\text { early-bifurcation } \\
\text { Non-classic with }\end{array}$ & $237(26.7 \%)$ & $117(26.3 \%)$ & $120(27.2 \%)$ & $12.81( \pm 2.4)$ & $12.7( \pm 2.5)$ & $12.79( \pm 2.39)$ \\
\hline early-bifurcation & $226(25.5 \%)$ & $113(25.4 \%)$ & $113(25.6 \%)$ & $07.53( \pm 1.7)$ & $08.0( \pm 1.9)$ & $07.74( \pm 1.84)$ \\
\hline
\end{tabular}

Table 2. Sphenoidal segmental angulations

\begin{tabular}{lllll}
\hline & $\begin{array}{l}\text { Total } \\
(n=886 \text { cerebral } \\
\text { angiograms) }\end{array}$ & $\begin{array}{l}\text { Right } \\
(n=445 \text { cerebral } \\
\text { angiograms })\end{array}$ & $\begin{array}{l}\text { Left } \\
(n=441 \text { cerebral } \\
\text { angiograms })\end{array}$ \\
\hline 1 & Oblique descent & $234(26.4 \%)$ & $132(29.7 \%)$ & $102(23.2 \%)$ \\
2 & Convexity downwards & $99(11.8 \%)$ & $58(13 \%)$ & $41(9.3 \%)$ \\
3 & Straight & $429(48.4 \%)$ & $191(42.9 \%)$ & $238(54.2 \%)$ \\
4 & Oblique course dorsad & $90(10.2 \%)$ & $47(10.6 \%)$ & $43(9.8 \%)$ \\
5 & Convexity dorsad & $32(3.6 \%)$ & $17(3.8 \%)$ & $15(3.4 \%)$ \\
\hline
\end{tabular}

on the right side. There were 241 males and 259 females with a mean age of 55.6 years (range 12-94).

\section{Bifurcation Site, Length, and Mirror Pattern of the Sphenoidal Segment}

The main MCA trunk bifurcation occurred along the horizontal segment and proximal to the genu (non-classic) in over $50 \%$ of all cases, and early bifurcation was noted in a quarter of these cases (Table 1).

The mean length of the main MCA trunk was $17.06 \mathrm{~mm}( \pm 3.84)$ in the classic pattern compared to $10.33 \mathrm{~mm}( \pm 3.31)$ in the non-classic pattern (Table 1$)$.

The mirror pattern of the main MCA bifurcation was analyzed in those 386 patients who had bilateral cerebral angiograms, and a mirror pattern was observed in less than half of the patients (159 patients, $41.2 \%$ ). The frequency was as follows: classic pattern (95 patients, $44.2 \%$ ), non-classic pattern without early bifurcation (28 patients, $24 \%$ ), and non-classic pattern with early bifurcation (36 patients, $32 \%$ ).

\section{Sphenoidal Course Angulation}

The most common course angulation pattern found was Straight, accounting for 429 cases (48.4\%), followed by oblique descent, found in 234 cases (26.4\%). Convexity downwards, oblique course dorsad, and convexity dorsad were found in 99 cases (11.8\%), 90 (10.2\%), and $17(3.8 \%)$, respectively (Table 2$)$.

Two-thirds of the total sample were found to have either a straight or an oblique descend course. We further studied the course angulation according to the patients' age, dividing them into three age groups: $<20$ years, $21-50$ years, and $>50$ years (Table 3 ). The mirror pattern was noted again only in a minority of patients (15-34\%) with the highest incidence in the 
Table 3. Sphenoidal segmental angulations with age ( $n=500$ patients)

\begin{tabular}{lllrr}
\hline & $\begin{array}{l}\leq 20 \text { years } \\
(n=15)\end{array}$ & $\begin{array}{l}21-50 \text { years } \\
(n=145)\end{array}$ & $\begin{array}{l}51-100 \text { years } \\
(n=340)\end{array}$ & $\begin{array}{l}\text { Mirror pattern } \\
\text { frequency }\end{array}$ \\
\hline 1. Oblique descent & $5(33.3 \%)$ & $27(18.8 \%)$ & $87(25.6 \%)$ & $40(34 \%)$ \\
2. Convexity downwards & 0 & $13(9 \%)$ & $36(10.6 \%)$ & $13(20 \%)$ \\
3. Straight & $6(40 \%)$ & $94(64.8 \%)$ & $169(49.7 \%)$ & $54(20 \%)$ \\
4. Oblique course dorsad & $4(26.7 \%)$ & $9(6.2 \%)$ & $33(9.7 \%)$ & $7(15 \%)$ \\
5. Convexity dorsad & 0 & $2(1.4 \%)$ & $15(4.4 \%)$ & $3(18 \%)$ \\
\hline
\end{tabular}

Table 4. LSA origin based on bifurcation pattern ( $n=886$ cerebral angiograms)

\begin{tabular}{lcc}
\hline Bifurcation pattern & Main trunk & $\begin{array}{c}\text { Main trunk and } \\
\text { divisional trunk }\end{array}$ \\
\hline Classic & $265(62.6)$ & $158(37.4)$ \\
Non-classic & $117(25.3)$ & $346(74.7)$ \\
$\quad$ Non-classic without early bifurcation & $91(38.4)$ & $146(61.6)$ \\
$\quad$ Non-classic with early bifurcations & $26(11.6)$ & $200(88.4)$ \\
Total & $382(43.11)$ & $504(56.8)$ \\
\hline
\end{tabular}

Values are presented as $n(\%)$.

oblique descent course pattern. A point biserial correlation analysis was performed to determine the correlation between age and the sphenoidal segment being straight (less frequently straight with age). We found a negative correlation that was statistically significant; as the patient ages, the sphenoidal segment becomes less frequently straight $(r=-0.07$, $p$ value $=0.02$ ) .

\section{LSA Takeoff}

Among the MCAs with classic bifurcation, the LSAs originated from the main trunk prior to its bifurcation in 265 cases (62.6\%); however, in the remaining 158 cases (37.4\%), the LSAs originated from both, the main MCA trunk and main MCA divisions. In the MCAs with non-classic non-early bifurcation, the LSAs emerged from the main trunk only in 91 cases (38.4\%) and from both main trunk and main MCA divisions in 146 cases (61.6\%). As expected, in the MCAs with early bifurcation, the LSAs originated from the main MCA and main MCA divisions in most cases $(200,88.4 \%)$, and in $26(11.6 \%)$ it originated from the main MCA trunk. When combined all together, the LSAs emerged from the main MCA trunk in 382 cases $(43.2 \%)$ and from the main MCA trunk and main MCA division in 504 cases (56.8\%) (Table 4).

\section{Discussion}

Contrary to the common knowledge in our studied population, we found that $<50 \%$ of the cases had a main MCA trunk bifurcation at the genu, in $<50 \%$ the horizontal segment was straight, and $<50 \%$ had the takeoff of the LSAs from the main MCA trunk. Conventional knowledge about the sphenoidal segment often highlights three main points. One, the sphenoidal segment, classically referred to as the M1 $[1,2,4,8]$. Two, the course angulation of the 
sphenoidal segment is usually straight running parallel to the sphenoidal ridge [3]. Three, the LSAs arise from the main MCA trunk [5].

Our findings about the MCA anatomy have confirmed prior cadaveric studies. Gibo et al. [3] reported the major bifurcation proximal to the genu in $86 \%$ of the studied hemispheres. Similar findings were noted by another study that examined 50 cerebral hemispheres, finding the bifurcation proximal to genu in $82 \%$ of the hemispheres, at the level of the genu in $8 \%$, and distal to the genu in $10 \%$ of the hemispheres [9]. On the other hand, Türe et al. [4] examined 20 human cadavers (40 cerebral hemispheres) and reported that the main bifurcation of the MCA occurred at the genu in $57.5 \%$ of the cerebral hemispheres; interestingly, $27.5 \%$ had the main bifurcation $4-10 \mathrm{~mm}$ distal to the genu, and in $15 \%$ the bifurcation occurred 5-8 $\mathrm{mm}$ proximal to the genu. Another important finding in our study and worth emphasizing was the change in the angulation course with age, being less frequently straight with aging. Our findings were similar to those observed by Krayenbühl et al. They found that the sphenoidal segment extends obliquely lateral and superiorly in children and juveniles compared to the older population in whom the artery runs obliquely lateral and downward. This could be explained by the increased tortuosity in the older population [7]. Vuillier et al. [10] assessed the course and divisional pattern of the sphenoidal segment of the MCA with the help of transcranial color-coded sonography in 50 patients $<55$ years of age. In their study, the sphenoidal segment ran straight in $52 \%$ of the cases. In the remaining $48 \%$, the segmental course was either anteriorly curved (19\%) or posteriorly curved (29\%). This is of importance during mechanical thrombectomy in patients with acute ischemic stroke as this aged population is the most commonly treated age group for ischemic stroke. A strongly curved sphenoidal segment of the MCA has been associated with significantly less successful recanalization compared to when the sphenoidal segment is straight $[11,12]$. In a prospective study, the authors studied the vessel branching and curvature in determining the success of recanalization based on indirect magnetic resonance imaging findings. They have concluded that a clot can assume the shape of the curved and tortuous MCA, making its retrieval difficult compared to a straight sphenoidal segment in which mechanical forces when exerted on the thrombus are more successful [11]. Schwaiger et al. [12], in their retrospective analysis, have reported that vessel anatomy, especially the curvature of the carotid terminus and increased angle between the M1 and M2, significantly affected the results of mechanical thrombectomy using a stent retriever. The patients who had unsuccessful recanalization (TICI 0-2a) had larger ICA/M1 and M1/M2 angles in the proximal vessel occlusion and significantly larger M1/M2 angles in distal vessel occlusions. Zurada et al. [13] also reported that the course of the sphenoidal segment was only slightly curved, but the variation and tortuosity could still lead to difficulty in relation to catheterization and embolization procedures.

Operators performing mechanical thrombectomy should be aware that it is quite common for the sphenoidal segment angulation to be present, and it may affect recanalization success rate. In addition, blind microwire navigation of the wire through the thrombus should be done carefully and not confuse the course of the microwire in the subarachnoid space in case of vessel perforation with different angulations. Microcatheter injection may be helpful in ensuring that the microcatheter tip is in the true lumen.

The LSAs are terminal branches that typically supply blood to the basal ganglia and its vicinity, and their occlusion results in the infarction of these structures [14, 15]. In our study, we observed the LSAs arising from the main trunk of the sphenoidal segment prior to bifurcation in $43.2 \%$ of the MCAs. In rest of the cases, they arose both from the main trunk and divisional trunk (56.8\%) with a much higher prevalence in early bifurcation (88.4\%). Table 5 summarizes LSA origin in neurosurgical anatomical studies and suggests that these arteries arise in the main MCA segment prior to its bifurcation in most cases (53-79\%). However, in the remaining cases, these also arise from the post-bifurcation segment, which would be 
Table 5. LSA origin based on neurosurgical anatomical studies

\begin{tabular}{lll}
\hline First author [ref.], year & $\begin{array}{l}\text { Cerebral } \\
\text { hemispheres } \\
\text { examined }\end{array}$ & Results \\
\hline Jain [23], 1964 & 600 & $\begin{array}{l}\text { Proximal main trunk: } 54.1 \% \\
\text { Distal main trunk: } 25.6 \% \\
\text { Post-bifurcational division: } 20.3 \%\end{array}$ \\
\hline Grand [24], 1980 & 36 & $\begin{array}{l}\text { Proximal half of the MCA before the main } \\
\text { division: } 14 \%\end{array}$ \\
& & $\begin{array}{l}\text { Distal half of the MCA before its main division: } 39 \% \\
\text { Branches of the MCA after its main division: } 47 \%\end{array}$ \\
\hline Tranriover [1], 2004 & 50 & $\begin{array}{l}\text { Pre-bifurcational M1 segment: } 62 \% \\
\text { Post-bifurcational M2 segment: } 15 \% \\
\text { M2 segment: } 2 \%\end{array}$ \\
\hline Umansky [16], 1984 & 68 & $\begin{array}{l}\text { Main trunk: } 79 \% \\
\text { Post-bifurcational: } 21 \%\end{array}$ \\
\hline Türe [4], 2000 & 40 & $\begin{array}{l}\text { Inferomedial aspect of the M1 segment: } 78 \% \\
\text { Frontal and temporal branch: } 18 \% \\
\text { Superior or inferior trunk of the M2 segment near the } \\
\text { bifurcation: } 4 \%\end{array}$ \\
\hline
\end{tabular}

consistent with our observations. It has previously been recommended that the M1 segment should be defined as the segment from the terminus ICA to the main MCA bifurcation, and the location of the occlusion should be localized to the proximal half when the LSAs are involved and to the distal half when spared [5].

The current existing nomenclature of the MCA is controversial. There is often discrepancy in the literature between the microsurgical and angiographic anatomy of the MCA (Tables 6, 7). Delion et al. [16] studied the pattern of branching of the main MCA trunk in 20 arteries of 25 cadavers, describing the M1 segment as the sphenoidal segment extending from the ICA bifurcation to the main MCA division, adjacent to the limen insulae, and the M2 as the insular segment extending from the MCA division to the periinsular sulci. However, Umansky et al. [17] studied the proximal segment of the MCA in 70 unfixed brain hemispheres of 35 cadavers, defining the main MCA trunk or M1 segment as the portion from the MCA origin to the main MCA bifurcation. In 1938, Dr. Erich Fischer [2] was the first one to define the M1 and M2 segments. He defined the M1 segment as the horizontal or sphenoidal portion extending from its origin to the genu, and this segment could include the bifurcation giving a pre-bifurcational and post-bifurcational M1 segment. This definition has been followed by others $[3,18]$. However, the most commonly accepted definition of the M1 segment is that segment that extends from its origin at the ICA bifurcation running laterally to the limen insulae, the point of bifurcation $[1,2,4,8,16]$. Moreover, the majority of neurointerventionalists has utilized in major stroke trials the later definition, assuming that the bifurcation occurs at the genu or limen insulae [5, 19-22].

As most ischemic strokes occur in the MCA distribution, the location of the obstruction determines the clinical outcome. As it is believed that emboli lodge at branching points, the more proximal the site of obstruction the larger the area at risk. Occlusions of the MCA distal to the bifurcation should lead to a lesser vascular territory injury. Typically, the superior division supplies the frontal and parietal regions, while the inferior division supplies the 
Table 6. MCA sphenoidal segment definition based on the anatomical studies

\begin{tabular}{|c|c|c|}
\hline First author [ref.], year & M1 segment definition & M2 segment definition \\
\hline Fisher [2], 1938 & $\begin{array}{l}\text { The horizontal initial segment of the artery } \\
\text { from the carotid internus to the } 90^{\circ} \text { angle/ } \\
\text { knee of the anterior cerebri media }\end{array}$ & $\begin{array}{l}\text { Insular segment that ascends towards } \\
\text { the back and with 2-3 main branches } \\
\text { that tightly rest on the brains' insular } \\
\text { region; on the lateral view, it runs in the } \\
\text { arterial axis (Moinz) of the brain, and in } \\
\text { the anterior view it ascends } \\
\text { almost vertically }\end{array}$ \\
\hline
\end{tabular}

Gibo [3], $1981 \quad$ Begins at the origin of the MCA and extends laterally within the depths of the Sylvian fissure; the segment terminates at the site of $90^{\circ}$ turn, at the genu, located at the junction of the sphenoidal and operculoinsular compartment of the Sylvian fissure; the M1 segment is further divided into pre-bifurcation (main trunk extending from the origin to the bifurcation) and post-bifurcation (runs parallel, diverging only minimal till it reaches genu)

Umansky [17], 1984
"Main trunk" of the MCA as a portion of the artery situated between its origin at the ICA bifurcation and its division what is called "main division"
Begins at the genu of the MCA where the trunks pass over the limen insulae, terminating at the circular sulcus of the insula

"main
division"

Türe [4], 2000

Rhoton [8], 2002

Extends from the ICA bifurcation to the main MCA bifurcation, which is located adjacent to the limen insulae

Begins at the origin of the MCA and extends laterally within the depths of the Sylvian fissure; it courses laterally, roughly parallel and

approximately $1 \mathrm{~cm}$ posterior to the sphenoid ridge in the sphenoidal compartment of the Sylvian fissure; the M1 is further subdivided into "pre-bifurcation" and "post-bifurcation"; the pre-bifurcation is composed of a single trunk extending from the origin to the bifurcation, and post-bifurcation trunks off the M1 segment, runs in parallel course diverging only minimally before reaching the genu
The arteries resulting from the main division are referred to as "secondary trunks" that are named "superior," "middle," or "inferior" based on the way in which the main trunk of the MCA is divided

Extends from the main bifurcation to the peri-insular sulci

Includes the trunk that lies on and supports the insula; the segment begins at the genu where the MCA trunks pass over the limen insulae and terminates at the circular sulcus of the insula

temporal, temporo-occipital, and angular regions [3]. Controversial data exist in this regard, but studies have not been controlled for the division affected, superior versus inferior, and whether the division is dominant [19-22]; yet, they are collectively referred as M2 occlusions. In addition, LSAs may also have variable origin, thereby affecting the outcome depending on their involvement given the lack of collaterals. 


\section{Interventional Neurology}

\begin{tabular}{l|l}
\hline Intervent Neurol 2019;8:231-241 \\
\hline DOI: 10.1159/000502545 & $\begin{array}{l}\text { c 2019 S. Karger AG, Basel } \\
\text { www.karger.com/ine }\end{array}$ \\
\hline
\end{tabular}

Khatri et al.: The Angiographic Anatomy of the Sphenoidal Segment of the Middle Cerebral Artery and Its Relevance in Mechanical Thrombectomy

Table 7. MCA sphenoidal segment definition based on the radiological studies in acute ischemic stroke trials

\begin{tabular}{|c|c|c|}
\hline $\begin{array}{l}\text { First author [ref.], } \\
\text { year }\end{array}$ & M1 segment definition & M2 segment definition \\
\hline $\begin{array}{l}\text { Saver[19], } \\
2015\end{array}$ & $\begin{array}{l}\text { M1 segment of the MCA is defined as the arterial trunk } \\
\text { from its origin at the ICA to the first } \\
\text { bifurcation or trifurcation into major branches, neglecting } \\
\text { the small temporopolar branch }\end{array}$ & n.a. \\
\hline $\begin{array}{l}\text { Jovin [22], } \\
2015\end{array}$ & $\begin{array}{l}\text { M1 MCA segment is defined as the first branch of the } \\
\text { intracranial ICA that courses } \\
\text { horizontally from its branching point off the ICA through } \\
\text { the Sylvian fissure up to the first } \\
\text { bifurcation distal to the origin of the } \\
\text { lenticulostriate arteries in the distal aspect of the Sylvain } \\
\text { fissure (limen insulae); large anterior temporal branches } \\
\text { arising proximal or at the level of the LSAs are not } \\
\text { considered M2 segments, and the remainder of the M1 } \\
\text { segment distal to the anterior temporal branch regardless } \\
\text { of the size of the latter is still considered M1 segment up to } \\
\text { its next bifurcation }\end{array}$ & \\
\hline $\begin{array}{l}\text { Campbell [20], } \\
2015\end{array}$ & Proximal MCI prior to bifurcation & $\begin{array}{l}\text { Distal MCA between bifurcation and } \\
\text { exit from the Sylvian fissure }\end{array}$ \\
\hline $\begin{array}{l}\text { Goyal }[21] \\
2015\end{array}$ & $\begin{array}{l}\text { The segment extends from the origin to the site of } \\
\text { bifurcation or trifurcation (the anterior temporal artery } \\
\text { is considered a branch of the M1 segment) }\end{array}$ & $\begin{array}{l}\text { This segment extends from the site of } \\
\text { bifurcation or trifurcation to the origin } \\
\text { of the cortical branches }\end{array}$ \\
\hline
\end{tabular}

Limitations to our study include the retrospective nature of the study and that the data pertain to a single center. However, our study of 500 patients is the largest series specifically emphasizing on the anatomical details of the sphenoidal segment of the MCA.

\section{Conclusion}

In the era of mechanical embolectomy using retrieval stents for acute embolic occlusion of the proximal segment of the MCA, familiarity with the anatomy and most common anatomical variants of the MCA segments are important.

It is imperative to develop an agreement in the nomenclature of MCA occlusions in acute ischemic stroke, to improve our current practice, and to develop future research given the clinical and radiological implications.

\section{Statement of Ethics}

This article does not contain any studies with animals/human participants performed by any of the authors.

\section{Disclosure Statement}

None of the authors have any conflicts of interest or financial ties to disclose. 


\section{Funding Source}

The authors did not receive any funding.

\section{References}

1 Tanriover N, Rhoton AL Jr, Kawashima M, Ulm AJ, Yasuda A. Microsurgical anatomy of the insula and the sylvian fissure. J Neurosurg. 2004 May;100(5):891-922.

2 Fischer E. Die Lagenweichungen der vorderen Hirnarteie im Gefassbild. Zentralbl Neurochir. 1938;3:300-12.

3 Gibo H, Carver CC, Rhoton AL Jr, Lenkey C, Mitchell RJ. Microsurgical anatomy of the middle cerebral artery. J Neurosurg. 1981 Feb;54(2):151-69.

4 Türe U, Yaşargil MG, Al-Mefty O, Yaşargil DC. Arteries of the insula. J Neurosurg. 2000 Apr;92(4):676-87.

5 Zaidat 00, Yoo AJ, Khatri P, Tomsick TA, von Kummer R, Saver JL, et al.; Cerebral Angiographic Revascularization Grading (CARG) Collaborators; STIR Revascularization working group; STIR Thrombolysis in Cerebral Infarction (TICI) Task Force. Recommendations on angiographic revascularization grading standards for acute ischemic stroke: a consensus statement. Stroke. 2013 Sep;44(9):2650-63.

6 Osborn AG. Introduction to Cerebral Angiography. Harper \& Row; 1980.

7 Krayenbühl H, Huber P, Yaşargil MG. Cerebral Angiography. Georg Thieme Verlag; 1982.

8 Rhoton AL Jr. The supratentorial arteries. Neurosurgery. 2002 Oct;51(4 Suppl):S53-120.

9 Tanriover N, Kawashima M, Rhoton AL Jr, Ulm AJ, Mericle RA. Microsurgical anatomy of the early branches of the middle cerebral artery: morphometric analysis and classification with angiographic correlation. J Neurosurg. 2003 Jun; 98(6):1277-90.

10 Vuillier F, Medeiros E, Tatu L, Cattin F, Bonneville JF, Moulin T. Assessment of the course and division patterns of the middle cerebral artery M1 segment. Transcranial power doppler compared with 3D time-of-flight magnetic resonance angiography at $3 \mathrm{~T}$. Cerebrovasc Dis. 2008;26(3):259-65.

11 Zhu L, Liebeskind DS, Jahan R, Starkman S, Salamon N, Duckwiler G, et al. Thrombus branching and vessel curvature are important determinants of middle cerebral artery trunk recanalization with Merci thrombectomy devices. Stroke. 2012 Mar;43(3):787-92.

12 Schwaiger BJ, Gersing AS, Zimmer C, Prothmann S. The Curved MCA: Influence of Vessel Anatomy on Recanalization Results of Mechanical Thrombectomy after Acute Ischemic Stroke. AJNR Am J Neuroradiol. 2015 May; 36(5):971-6.

13 Zurada A, Gielecki J, Tubbs RS, Loukas M, Maksymowicz W, Cohen-Gadol AA, et al. Three-dimensional morphometrical analysis of the M1 segment of the middle cerebral artery: potential clinical and neurosurgical implications. Clin Anat. 2011 Jan;24(1):34-46.

14 Marinkovic SV, Milisavljevic MM, Kovacevic MS, Stevic ZD. Perforating branches of the middle cerebral artery. Microanatomy and clinical significance of their intracerebral segments. Stroke. 1985 Nov-Dec;16(6):1022-9.

15 Marinkovic S, Gibo H, Milisavljevic M, Cetkovic M. Anatomic and clinical correlations of the lenticulostriate arteries. Clin Anat. 2001 May;14(3):190-5.

16 Delion M, Mercier P, Brassier G. Arteries and Veins of the Sylvian Fissure and Insula: microsurgical Anatomy. Adv Tech Stand Neurosurg. 2016;43:185-216.

17 Umansky F, Juarez SM, Dujovny M, Ausman JI, Diaz FG, Gomes F, et al. Microsurgical anatomy of the proximal segments of the middle cerebral artery. J Neurosurg. 1984 Sep;61(3):458-67.

18 Kahilogullari G, Ugur HC, Comert A, Tekdemir I, Kanpolat Y. The branching pattern of the middle cerebral artery: is the intermediate trunk real or not? An anatomical study correlating with simple angiography. J Neurosurg. 2012 May;116(5):1024-34.

19 Saver JL, Goyal M, Bonafe A, Diener HC, Levy EI, Pereira VM, et al.; SWIFT PRIME Investigators. Stent-retriever thrombectomy after intravenous t-PA vs. t-PA alone in stroke. N Engl J Med. 2015 Jun;372(24):2285-95.

20 Campbell BC, Mitchell PJ, Kleinig TJ, Dewey HM, Churilov L, Yassi N, et al.; EXTEND-IA Investigators. Endovascular therapy for ischemic stroke with perfusion-imaging selection. N Engl J Med. 2015 Mar;372(11):1009-18.

21 Goyal M, Demchuk AM, Menon BK, Eesa M, Rempel JL, Thornton J, et al.; ESCAPE Trial Investigators. Randomized assessment of rapid endovascular treatment of ischemic stroke. N Engl J Med. 2015 Mar;372(11):1019-30.

22 Jovin TG, Chamorro A, Cobo E, de Miquel MA, Molina CA, Rovira A, et al.; REVASCAT Trial Investigators. Thrombectomy within 8 hours after symptom onset in ischemic stroke. N Engl J Med. 2015 Jun;372(24):2296-306.

23 Jain KK. Some observations of the anatomy of the middle cerebral artery. Can J Surg. 1964 Apr;7:134-9.

24 Grand W. Microsurgical anatomy of the proximal middle cerebral artery and the internal carotid artery bifurcation. Neurosurgery. 1980 Sep;7(3):215-8. 